\title{
Research into College Student Information Management System based on Web
}

\author{
$\mathrm{Hu}$ Guozhu* \\ Liaoning Mechatronics College \\ Dandong Liaoning, China \\ e-mail: arnold0110@sina.com \\ * Corresponding Author
}

\begin{abstract}
Development of College Student Information Management System is an inevitable trend of the current campus information technology and an important means. Based on the information for college students' detailed analysis of the architecture, the main function of the system on the basis of the detailed design, design university student information management system for Web-based. The system is based on the campus network, using .Net technology and SQL database technology, B / S of the multilayer structure. System interface is friendly, simple operation, security and scalability, while providing office software interacts with the EXCEL interface, which greatly improves the efficiency of college student management.
\end{abstract}

Keywords-Web; student information management; management system; NET; Multi-level B/S

\section{INTRODUCTION}

Information management system is a way to improve efficiency and change important tool works, when network technology further into all aspects of society, there has to double (C/S) architecture and multi-layer (B / S) architecture information management system, making people's lives undergoing tremendous change. Meanwhile, with the campus LAN and accelerate the process of building digital campus to campus network-based information management system based on B / S structure is widely used in the field of Higher Education. Information management system to achieve better open the system, multi-user management, connected to the Internet, greatly improving the work efficiency and quality of work. Therefore, based on the actual technical modernization and campus network construction, design a kind of B / S structure architecture student information management system is an important way to achieve the current student data management information construction.Student Information System for students to use and management of information is very important. In this paper, the Liaoning Institute of Mechatronic Technology student information management, for example to study, in view of the current situation and problems of daily management of student information management work involved, the Student Information Management Information management is divided into static and dynamic information management. Static information management mainly refers to students basic information, such as: management name, gender, nationality, profession, class, family member information and other basic information; dynamic information management is primarily a personal information form for students in the university, such as: scholarship information, student aid information, student loan information, student second classroom activities, student dormitory management and other management information.
And the role of student information management associated mainly: the student, instructor, student administrator at all levels and functions section administrator, and the formation of student information that is associated with the outcome of these roles and role.

\section{SYSTEM FUNCTION DESIGN}

According to the students' information management role, we can see that the functional requirements of the system is the management of students' information management and the management of the system. The former is the students, counselors, college administrators, functional departments and administrators and system administrators as a result of the event to trigger student information, which is the system for student information management needs and data maintenance. Therefore, the system needs to have the following functions:

- Information extraction and absolute increase function. That is, the students' basic information and dynamic information of the browsing and production, the main function for the "Browse", "add" and "import".

- Step by step audit function. In the process of management, the need to carry out the logic of the validity of information, in order to produce information, to provide effective information to the relevant departments. Therefore, different roles have different permissions, the user according to their own authority to conduct data review, thus forming the final student information.

- Information maintenance function. In the process of exchanging information, it can cause data errors due to various reasons. Therefore, it is necessary to allow the system to have the role of the data error correction, that is, the "Edit" function.

- Information retrieval, export and report output. Information in the process of management, the need for mass information to collect or output, and according to the type of information with accurate or fuzzy search, and Microsoftofice office software to meet the information retrieval, export and report output function. Information in the process of management, the need for mass information on the condition of the collection or output, and according to the type of information has a precise or fuzzy search, and Microsoftofice office software to meet the needs of the data. All kinds of required data requirements. 
- Statistical analysis of information. Any decision is based on a certain information basis, the student information once formed, it has relative stability, therefore, in some decision-making, the need to student information as the basis, which requires the system has the function of statistical analysis, so as to realize the useful information extraction.

- System maintenance function, which refers to the system in the process of running, the need to have the basic setup of the system, the administrator maintenance, data backup, data recovery, data initialization of these functions to improve the applicability of the system.

\section{SySTEM TECHNICAL ROUTES AND RELEVANT TECHNOLOGIES}

\section{A. System Technical Routes}

University student management has many characteristics, such as wide range of processes, diversity of basic data information, management personnel role and complex authority. So, the system must realize the function of the system's internal opening, multi-platform compatibility, and Internet connection. The system decides to use the multi-layer $\mathrm{B} / \mathrm{S}$ service system with the user interface layer, application logic layer, data access layer and data layer. Web server uses Windows2000 and IS5.0, the database server uses Windows2000 and SQL2005, the application logic layer and database access module which is connected with the database and Web server are arranged in the middle layer server which is formed by the Web server [1].

\section{B. ASP.NET \& C Language}

\section{1) ASP.NET \& C Language}

ASP.NET is a new generation of WEB application development system based on .NET Framework technology, and it is a new technology to build dynamic Web applications. You can use any.NET compatible language to write ASP.NET applications [2,3]. This system uses the $\mathrm{C}$ language as the application programming tool. $\mathrm{C}$ is a simple, safe, and object-oriented programming language for the development of.NET. It has absorbed the advantages of $\mathrm{C}++$ 、 VisualBasic 、 Delphi、 Java and other languages, which embodies the function and essence of the latest program design technology. The object model of $\mathrm{C}$ has been re designed for Internet, which uses the.NET framework [4]; The.NET framework provides a powerful, easy to use, logical and consistent programming environment for the $\mathrm{C}$ framework. 2) ADO.NET Database Access Technology

ADO.NET ADO is an epoch-making improvement, it provides a platform for interoperability and scalable data access. In the.NET framework of the System. Data namespace and its sub space, there are some classes, which are collectively referred to as ADO.NET. Using ADO.NET can easily retrieve and process data from Microsoft Acces, Microsoft SQLServer or other databases, and update the data in the database [5].

\section{3) SQLServer2005 Database Technology}

The vast majority of Web applications require background database support. In the background database, SQLServer and Acess are the most frequently used databases. SQLServer database is generally used in the implementation of large application systems. In particular, SQLServer2005, which can provide integrated information management solutions, can help organizations of any size to create and deploy a more scalable, reliable and secure enterprise applications, reduce the complexity of database applications, deployment and management, and to achieve the maximum efficiency of IT. In addition, it can also cross a variety of platforms, applications and devices to achieve data sharing, and then simplify the internal system and external system connection, some powerful integrated business intelligence solutions.

\section{SYSTEM IMPLEMENTATION}

\section{A. Database Implementations}

\section{1) Create Database}

First create the database info stu, to save all the data in this system. The script for creating the database is as follows:

create data base stu info

go

2) Establish the E-R diagram and design the corresponding data table

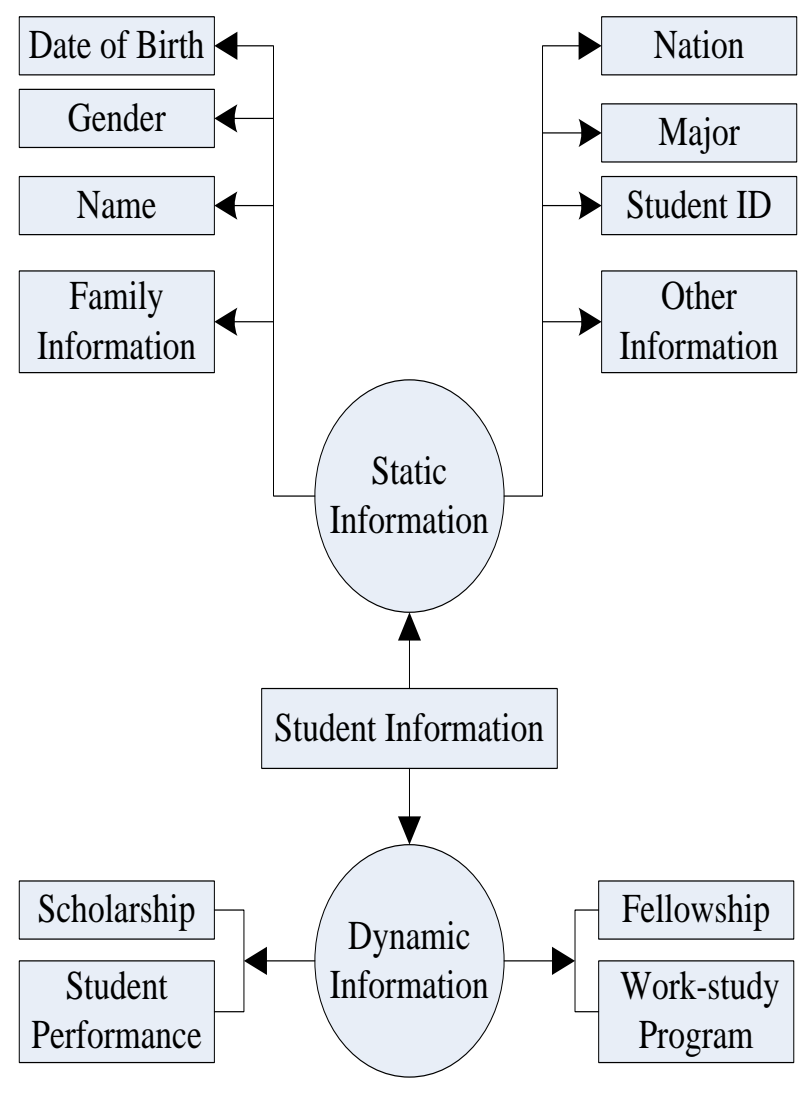

Figure 1. The E-R diagram of student information

According to the system function, this system database includes three kinds of data information, such as 
student basic information data, student information data and system information. According to students' information to establish the basic information of students: base stu, used to store the basic information of students.

\section{3) Student information management design}

Students' dynamic information table is used to record the students' behavior information, such as scholarships, etc., which is the main business of this system. Such as scholarship information management mainly include: name, institution, level, amount, evaluation reasons, etc.

\section{B. System Function Implementation}

Microsoft.NET technology basic design idea is to connect to the Internet connection to a single site to the computer, equipment and service groups, the Internet as a new generation of operating system, so as to achieve the freedom of information from time to time, space [8]. This is also the system's design goals and requirements, the system is faced with the user base is very complex, the terminal is not the same access.

Below is a variety of different users need to have the function: ordinary users: students, data operation range for my information. The main function is the application of the dynamic information of the students, the personal basic information, the report output of the basic information and the information retrieval.

Level 1 administrator: the instructor, the data operation ranges of the student information. The main function is to browse the students' information, the dynamic information submitted by the students to review and submit, the application of the new dynamic information, the basic information of the students, the students' information, the information of the students' information, the report output of all kinds of information.

Level 2 administrator: that is, the Department Administrator, data operation ranges of the students in the Department of information. The main function is to browse, edit, search, add student information, and to the instructor audit and draw the dynamic information of the audit approved or submitted.

Level 3 administrator: the administrator of the student committee, the data range is the database all student information. Its main function is to add, browse, delete, edit, audit, approval, import, export, report output and so on.

Level 4 administrator: the system administrator, the system administrator privileges, but the general situation is not the management of student information. Its main function is the system data management and system management.

\section{System Module Implementation}

According to the functional analysis, the system should have 6 main functional modules are as follows:

- System login module. User authentication function, through the user name and password authentication, refused to authorize the user login system, and according to the user class to grant different administrative authority.

- Information management module. Student dynamic information of the application, review step by step, approval, export and backup; information query functions: provide information related to the students' basic information, student achievement information, the daily attendance information, class information activities, teachers and students to exchange information, poor student information, student leaders and student award punishment information query; information maintenance function: according to the results of a query, the specified information to complete data update operation; deleting invalid information.

- Information statistical analysis module. Statistics, analysis and report output of student information, information output function, to specify the information, according to a predetermined or custom format to complete the print output.

- User management module. User management functions, including adding users, delete users, user name and password changes, etc.

- System setting module. Realize the basic settings of the system, such as college, professional, class, etc.

- Data maintenance module. Initialization, recovery and backup of system data.

\section{Connection with EXCEL}

\section{Connection with EXCEL}

Microsoft Office series products are the most commonly used office software, the system to achieve the connection with the office software, is the basic requirements of the system design. Using ASP.NET technology and SQL background database information management system, the need to use the report processing system module, to achieve the report generation. Its process is: Web server through ADO.NET and SQL database connection, read data, and then call the server Application Excel object, open the existing Excel template, the data is written into the specified Excel workspace, and finally generate a temporary Excel report file, to achieve the report output. At the same time, the Image data in the SQL database table can store data stream type data, use ASP.NET to convert the Office file into data stream into the database, and then convert the data from the data stream into the Office file to the Excel file.

\section{E. System Data Recovery and Backup}

Stable operation of the system, the need to consider the accident occurred in the event of data, and therefore, the system design, the design of the data backup and data recovery function, system administrators can perform data backup and recovery in the Web. At the same time, the use of SQL data backup function can be carried out in the server side of the system database backup and recovery, so as to ensure the stability of the system data.

\section{F. System Security Considerations}

This system is based on the campus network, the use of $\mathrm{B} / \mathrm{S}$ multi-layer structure and hierarchical design of the user type, making the system running safe and reliable.

First, database security. Based on the B/S architecture, the structure itself has a certain security design, system code all on the server, the client code is dynamically downloaded to the client, only the code on the server to access the database, the client cannot access, which can protect the security of the database server [9].

Secondly, the system is deployed in the campus network, relying on the campus network of powerful 
firewall function, for the system to run and provide a strong security for the database.

Once again, the role based access control mechanism [10]. To the students, counselors, college administrators, functional departments and system administrators of the sub level design, a strict definition of the management authority and functions of all kinds of users, so that data security has been better protected.

\section{CONCLUSIONS}

The man-machine interface is friendly, the operation is simple, and has good stability, security and expansibility. Make the university student information management work more standardized, functional management personnel, counselors, students and other different role information exchange ability, and in the whole school to achieve the sharing of information resources to achieve a variety of student information data, making the university students management work more efficient, reasonable and orderly.

\section{ACKNOWLEDGMENT}

This work was financially supported by Liaoning Province Education Science "Twelfth Five Year Plan" under Grant (JG15EB068).

\section{REFERENCES}

[1] Microsoft Corporation. Microsoft SQLServer TM 2000 [M]. Beijing: Science Press, 2000.

[2] JefProsise..NET Technical Insider [M]. Beijing: Tsinghua University Press, 2003.

[3] Qiu Yan, Wang Qinkin. Key technology of system integration with.NET[J]. Computer Engineering and Application, 2003(24):136-138.

[4] Chen Chuanbo, Xia Yibing. A right management system model based on ASP.NET technology and three tier network architecture [J]. Computer Engineering, 2003, (12):101-102.

[5] Wang Huajie, Li Lusong. Proficient in C Database Development [M]. Beijing: Tsinghua University Press, 2004.

[6] Yang Pingle, Liu Shusen. The design and implementation of student information management system based on ADO.NET [J] Computer Technology and Development, 2010(5):238-241.

[7] Yue Xuejun, Li Xiaoli. Web Application Development Tutorial ASP.NET+ SQLServer[M]. Beijing: Posts and Telecom Press, 2009.

[8] Liang Xiaoxiao, Wei Chonggang. The design and implementation of university student information management system based on Web [J]. Journal of Sichuan University of Science \& Engineering,2010,23(6): 699-703.

[9] John W.Satzinger. System Analysis and Design [M].Beijing : China Machine Press, 2006.

[10] Zheng Huisheng, Kang Qi. Application Research of.NET multi-tier architecture in practical engineering $[\mathrm{J}]$. Software Guide, 2010(6):136-137. 